\title{
Study on the Capital Asset Pricing Model(CAPM): literature review and possible improvements
}

\author{
Tianyang $\mathrm{Xu}$ \\ Suzhou North America High School, China
}

\begin{abstract}
Capital Asset Pricing Model is one of the most classic financial models used by investors to predict the relations between risks and returns. However, with the rapid growth of global market, international corporations and fictitious assets, the whole global market becomes more complicated. For the stock markets, with more factors affecting the risks and expected returns, will these novel changes affect and make those classic financial models obsolete? This paper discusses the history of the Capital Asset Pricing Model and and studies the adaptability, assumptions, and formula of Capital Asset Pricing Model and the methods that could be used to improve this model. By carrying out data analysis, it is found out that the Capital Asset Pricing Model has shown poorer ability to predict the expected returns and risks comparing to other models that take more factors into account, such as the Fama-French Three-Factor Model. As a result, Fama-French Three-Factor Model is analyzed in this paper to find why it provides more accurate results that fit the real situations. After that, improvements that could be added on the Capital Asset Pricing Model are proposed based on the analysis on Fama-French Three-Factor Model.
\end{abstract}

Keywords: CAPM; Fama French; pricing theory; model stock.

\section{Introduction}

\subsection{Background}

The Capital Asset Pricing Model (CAPM) is a famous and classic model that helps economists and investors to find out the relation between market risk and expected return. Since the model was gradually perfected during the 1960s, it has always been a debatable model. This paper will mainly(briefly) discuss the history(development) of CAPM and its fitness(functionality ) for today's stock markets, and then how to improve(future developments) the CAPM.

Currently, investors can easily access the stocks in stock markets worldwide, such as the Nasdaq and the Shanghai Stock Exchange. When investors intend to buy or sell their stocks, they have to take the potential of stocks into account or try to predict risk and interest to earn more profits and also reduce losses. However, before the introduction(invention) of CAPM, investors did not have a clear cognition yet that how would the risk affect a company's cost of capital. In the other words, the profits(profitability). Later, thanks to a series of excellent economists, their theories gradually evolved into the CAPM, providing a better way for investors the anticipate their stocks' risk and relative profits. In this paper, the history(progress for development) of CAPM will be introduced.

Unfortunately, the development of models is always slower than the growing pace of markets. Most models are outdated, so do the CAMP. This paper will combine both theoretical analysis and comparison to determine how the CAPM works and whether the CAPM will still work appropriately today.

Tracing back to the year 1958, Modigliani and Miller proposed the well-known Modigliani Miller Models. The models inspired Treynor, who was reading the MBA (Master of Business Administration) at the University of Harvard, to write a paper called "Market Value, Time, and Risk", which is the embryonic form of CAPM. Later, Miller and Modigliani noticed Treynor's work, and advised him to continue his work in MIT (Massachusetts Institution of Technology), where Treynor put forward the "Toward a Theory of Market Value of Risky Asset".

On the other side, William Sharpe was also researching the portfolio. Around the year 1960, Modigliani advised Treynor and Sharpe to exchange their paper. Sharpe approved Treynor's paper but was astonished that why did not Treynor publish it. In the year of 1964, Sharpe's CAPM was finally published to come out on the scene. 
Afterward, John Lintner, Jan Mossin, and Fischer Black gradually perfected the CAPM. In the year of 1990, Sharpe won the Nobel Memorial Prize in Economic Sciences due to his contribution to the CAPM. Surprisingly, Treynor did not win that prize which he deserved. Treynor said that "I thought that of Sharpe was going to publish, what's the point of my publishing my paper?" However, the significant contributions made by Treynor will be always remembered.

\section{Literature review}

\subsection{Introduction}

The stock market had experienced a series of revolutions, and the market is still keeping evolving. In the stock market, companies raise money by selling the shares of ownership of a certain company. Historically, stocks and the prices of other assets are the most important parts of economic activities. Stock markets are deemed the major standard of one nation's economic power both in the past and in present days. For example, the increase in stock price is usually concerned with the increase in investment.

The main defect of the CAPM is that it can be only used under a series of assumptions. For example, it assumes that every investor is an expert in investing, making clever decisions, the market information is transparent, and there is no limitation that the investors can completely sell short or buy-in. Nevertheless, these assumptions are unattainable in reality. Moreover, the CAPM assumes that the whole market is effective, which means the stocks that are not sensitive to the systematic risks will not exist. As a result, $\beta$ could not help investors with the appropriate stocks; if $\beta$ could, that will disprove the CAPM.

When we focus on the calculation of CAPM, we will find out that all the risks existing in the market need to be involved in the calculation, while it is merely impossible in the reality too.

Furthermore, the CAPM is only able to hedge the risk brought by single stock; When the whole market shows a depressive trend, which is caused by the unavoidable systematic risk, the CAPM is not able to protect investors anymore.

Considering all these flaws of CAPM, it seems not to be a reliable model for investors anymore.

\subsection{Purpose of study}

This study is aim among other existing empirical researches and try to summarize them to concludes the possible reasons why CAPM be less effective.

\subsection{Fundamental Theories}

\subsubsection{CAPM model}

The CAPM model is used to calculate the expected return of certain investment portfolio or single investment. Firstly, we need to understand the meaning of each factor in this formula.

$$
\mathrm{Ri}=\mathrm{Rf}+\beta(\mathrm{Rm}-\mathrm{Rf})
$$

$\mathrm{Ri}$ : The expected return of certain investment portfolio or single investment.

Rf: The risk free (-) rate, which means the investors do not need to worry about any risks.

$\beta$ : relation between investment and market

$\mathrm{Rm}$ : The market return, which means the average investment risk of all the investment products in the market.

Rm-Rf: Market risk premium, which means the extra profit earned by investors if they put their capital into the market instead of the bank(risk free).

Generally speaking, in financial markets, higher risk means higher return, and vice versa. Imaging if investors buy the government security or save their money in the bank, it would be risk free for these investors, due to the fact that it is rare to see that countries or banks would bankrupt easily. However, investors are eager to earn more. 
Table 1 Fixed-term interest rate of the Bank of China updated in the September 17, 2021

\begin{tabular}{|c|c|}
\hline Three month & $2.850 \%$ \\
\hline Half a year & $3.050 \%$ \\
\hline One year & $3.250 \%$ \\
\hline Two years & $3.750 \%$ \\
\hline Three years & $4.250 \%$ \\
\hline Five years & $4.750 \%$ \\
\hline
\end{tabular}

In stock markets, according to the Modern Portfolio Theory proposed by economist Harry Markowitz, investors can represent risks with variance or standard deviation. On the graph of one stock's trend, when the variance varies frequently and always escapes from its median line, the variance is thought to be large, which means higher risk.

\subsubsection{FAMA-French}

In 1992, Fama and French studied the factors that determine the difference in the return of different stocks in the stock market in the United States and found that the beta value of the stock market cannot explain the difference in the return of different stocks, but the market value, book-to-market ratio, and price-to-earnings ratio of listed companies can explain the difference in stock returns. Fama and French believed that the excess returns are compensation for risk factors that are not reflected by $\beta$ in CAPM.

Later in 1993, Fama and French pointed out that a three-factor model can be established to explain stock returns. The model illustrates that the excess return of an investment portfolio (including a single stock) can be explained by its exposure to three factors, which are: market asset portfolio (Rm - Rf), market value factor (SMB), book-to-market value ratio Factor (HML). This multi-factor equilibrium pricing model can be expressed as

$$
r_{\mathrm{Pt}}=\propto_{\mathrm{P}}+\mathrm{b}_{\mathrm{p}} \mathrm{r}_{\mathrm{Mt}}+\mathrm{s}_{\mathrm{P}} \mathrm{SMB}_{\mathrm{t}}+\mathrm{h}_{\mathrm{P}} \mathrm{HML}_{\mathrm{t}}
$$

$r_{P t}$ : Returns on portfolio $P$ in excess of the risk-free rate at time $t$

$\mathrm{r}_{\mathrm{Mt}}$ : Returns on an equity portfolio in excess of the risk-free rate

$\mathrm{SMB}_{\mathrm{t}}$ : (small minus big)Difference in returns on a portfolio of small stocks and a portfolio of large stocks

$\mathrm{HML}_{\mathrm{t}}$ :(high minus low)Difference in returns on a portfolio of high book-to-market stocks and a portfolio of low book-to-market stocks

$\propto_{\mathrm{P}}, \mathrm{b}_{\mathrm{p}}, \mathrm{s}_{\mathrm{P}}, \mathrm{h}_{\mathrm{P}}$ : Estimate coefficients

\subsection{Current studies}

According to Graham Bornholt's research on CAPM. He discovered that, the Camp's momentum, beta, value anomalies during 1996-2003. The research was based on 48 industries from the United States. However, the analysis did not include the recent market, because it was done about twenty years ago. In the current market, industries have been developed into data science like robots and the cloud. More industry comes to the new services market. For example, Alibaba established a huge e-commerce platform and changed the way that people consume. For another example, Facebook(meta) redefined communication around the world, making it easier for people to exchange information. Those companies should have a new method to estimate they are profitability. The ways how companies profit and operate have changed a lot since 2003. The study only focused on the American market, which is a developed nation with a totally free market. However, there are still undeveloped countries and developing countries where mature markets do not exist. As a result, the CAPM may not work effectively under different situations. 
Another research done by Zainul Kisman and Shintabelle Restiyanita in 2015 tested if CAPM or Arbitrage Pricing Theory(APT) would better predict the effect of the market excess return on LQ45 companies stock returns. By applying multiple regression, they finally concluded that APT shows extraordinary ability to predict stock returns, while CAPM is not able to accurately predict it. As a result, it is shown that CAPM may not suit current stock markets anymore; So, choosing APT would be the first choice for investors. Compared to CAPM which only takes the portfolios into account, more factors are considered in APT, such as the growth in GDP and inflation. Since this research was done in 2015, we still believe that the conclusion still works today, and CAPM may need to be improved so that it can fit today's stock market better, to provide investors with more precise predictions.

The research done by Mahnoor Sattar in 2017, the CAPM Vs Fama-French Three-Factor Model: An Evaluation of Effectiveness in Explaining Excess Return in Dhaka Stock Exchange illustrates the idea that the Fama-French model is better at predicting excess return than CAPM. In this research, Mahnoor adopted both CAPM and Fama-French Three-Factor Model to predict the excess return of 5 cement companies in 10 years, from 2004 to 2014. After applying simple and multiple linear regression analysis, Fama-French shows its superb ability to predict excess return. We can easily see that when using the Fama-French model, more factors are taken into account than using CAPM. So, we can probably add more calculations and factors to CAPM to make it adjust more complicated stock market nowadays.

In the research done by Georges, Jingyuan, and Cedric on May 8, 2012, it was emphasized the importance of measuring the dependence between consumption and asset returns. They used the concept of excepted dependence and verify covariates and risks. Understanding a deeper level of risk dependence and risk behavior sequence is the key to asset returns and corresponding premiums. Risk dependence and real behavior can eliminate hidden problems uncovered, and partially solve the real premium problem. So, as the discussion emphasized, CAPM still needs to be perfected in nowadays stock market.(Dionne, 2012)

The question toward CAPM raised by Banz, FAMA\& FRENCH, and Jegadeesh \& Titman shows a lot of other risk factors could affect the return but CAPM models did not take into considerations. Such as study on the value and returns determine the size of investment also affects the returns. (The Relationship between Return and Market Value of Common Stocks, (Adedeji, 2002) Another study from Value Portfolio (Basu (1997), Fama \& French (1992))2 also determined there are a lot of investment combinations cloud not be clarified by CAPM. The Momentum Portfolio(The Conservatism Principle and the Asymmetric Timeliness of Earnings1, 1997) also shows the momentum strategies also give unpredictable returns. All those studies lead to a hypothesis, the CAPM model is right in its logic, but it is lacking risk factors. This means more risks affect the result but are not concluded in the model.(JSTOR: Access Check, n.d.)

\section{Conclusions}

By comparison of CAPM model and other models, especially FAMA-French, there is a conclusion of CAPM model is logically correct but lacks risk factors. Just like the FAMA-French model with more multiple risk factors. This also indicates that there are multiple risk factors in the markets. The assumption of CAPM does not hold for real stock markets. CAPM model does not hold for a lot of situations highly possible due to its lack of possible risk factors. Further research on adding risk factors could make CAPM more realistic.

\section{Possible Improvements}

Here is concluding possible risk factors that should be added due to differences between CAPM's assumptions and real markets. 
Not all investors are rational and have the same pieces of information, due to the popular use of options and futures. There are a lot of emotional investors. Sometimes the group is big enough to change the market trend.

Currently China is the second-largest market and second position on foreign direct investment. However, the regulation on investment does not allow short sales. This could affect investors' choices and should involve other risk factors.

\section{References}

[1] G-EMC Policy. (1970). IEEE Transactions on Electromagnetic Compatibility, EMC-12(4), 180e. https://doi.org/10.1109/temc.1970.303059

[2] Dionne, G. (2012, May 8). An Extension of the Consumption-Based CAPM Model. Posidon. Retrieved November 26, 2021, from https://papers.ssrn.com/sol3/papers.cfm?abstract_id=2018476

[3] The relationship between return and market value of common stocks. (1981, March 1). ScienceDirect. $\begin{array}{llll}\text { Retrieved November } & 26, & 2021, & \text { from }\end{array}$ https://www.sciencedirect.com/science/article/abs/pii/0304405X81900180

[4] Adedeji, A. A. (2002). A Cross-sectional Test of Pecking Order Hypothesis Against Static Trade-off Theory on UK data. SSRN Electronic Journal. Published. https://doi.org/10.2139/ssrn.302827

[5] The conservatism principle and the asymmetric timeliness of earnings1. (1997, December 1). ScienceDirect. Retrieved November 26, 2021, from https://www.sciencedirect.com/science/article/abs/pii/S0165410197000141

[6] JSTOR: Access Check. (n.d.). Jstor. Retrieved November 26, 2021, from https://www.jstor.org/stable/222579

[7] Graham Bornholt (2013) The Failure of the Capital Asset Pricing Model(CAPM): An update and discussion, from http://ssrn.com/abstract=2224400 